$16^{\circ}$ USIHC - Congresso Internacional de Ergonomia e Usabilidade de USIHC Interfaces Humano Computador

\title{
SOBRE APROPRIAÇÃO, MEDIAÇÃO, IDENTIDADE, PRAZER E INTERAÇÃO: CONSIDERAÇÕES TEÓRICAS SOBRE ERGONOMIA E DESIGN COMO MEDIADORES DA RELAÇÃO HOMEM X OBJETO - UM ESTUDO COM EMBALAGENS DE PRODUTOS ALIMENTÍCIOS
}

\author{
ABOUT APPROPRIATION, MEDIATION, IDENTITY, PLEASURE AND \\ INTERACTION: THEORETICAL CONSIDERATIONS ON \\ ERGONOMICS AND DESIGN AS MEDIATORS OF THE \\ RELATIONSHIP MAN X OBJECT - A STUDY WITH PACKAGING OF \\ FOOD PRODUCTS
}

TAVARES, Luciano César Cerveira Tavares (1)

Universidade Federal do Maranhão, mestrando. email: raslucainot@gmail.com

CAMPOS, Lívia Flávia de Albuquerque (2) Universidade Federal do Maranhão, Doutora. email: livia.albuquerque@ufma.br

DINIZ, Raimundo Lopes (3)

Universidade Federal do Maranhão, Doutor. email:rl.diniz@ufma.br

CASTRO, Erika Veras (4)

Universidade Federal do Maranhão, Mestra. email: erika.ufma@gmail.com

Percebe-se que o homem, enquanto usuário de produtos e artefatos que o cercam, tem sido mais observado (tanto no campo do design quanto da ergonomia), em seus aspectos emocionais e afetivos. Este artigo é de caráter teórico-descritivo, com objetivo de discutir e investigar as noções de apropriação, mediação, identidade, prazer e interação, apoiados nos estudos sobre Análise sensorial e de conforto, de Pereira (2004) e nos estudos relacionados sobre a Experiência amorosa entre pessoas e objetos, de Russo; Hekkert (2008), além evidenciar o papel da Ergonomia e do Design como campos de conhecimento que mediam a relação homem x objeto. A investigação também se deu no âmbito empírico, por meio de pesquisa de campo, realizada afim de confrontar os conceitos desenvolvidos neste estudo, com a relação de consumo entre o homem e os produtos alimentícios. 


\section{$16^{\circ}$ \\ ERGODESIGN USIHC CINAHPA}

$16^{\circ}$ Ergodesign - Congresso Internacional de Ergonomia e Usabilidade de Interfaces Humano Tecnológica: Produto, Informações Ambientes Construídos e Transporte

$16^{\circ}$ USIHC - Congresso Internacional de Ergonomia e Usabilidade de Interfaces Humano Computador

CINAHPA | 2017 - Congresso Internacional de Ambientes Hipermídia para Aprendizagem.

It is noticed that the man, as user of products and artifacts that surround him, has been more observed (both in the field of design and ergonomics) in his emotional and affective aspects. This article is of a theoretical-descriptive nature, with the objective of discussing and investigating the notions of appropriation, mediation, identity, pleasure and interaction, supported by the studies on Sensory and Comfort Analysis, by Pereira (2004) Of Russo; Hekkert (2008), in addition to highlighting the role of Ergonomics and Design as fields of knowledge that mediate the relationship man vs. object. The research also occurred in the empirical field, through field research, carried out in order to confront the concepts developed in this study, with the relationship of consumption between man and food products.

\section{Introdução}

O homem, ao se relacionar e interagir com o mundo, busca incessantemente elementos que favoreçam essa relação. Ele encontrou nos objetos cotidianos uma resposta que cumpre essa necessidade, e desenvolveu estudos que tentam suprir tais anseios. Essa busca levou ao desdobramento de uma atividade que é feita para comunicar consigo mesmo e com os outros, uma atividade constante "[...] e transversal a cada cultura, $[. .$.$] em cada época conhecida, que$ poderíamos fazer coincidir com o passado do nosso projetar atual destinado aos artefatos para comercialização (mercadorias), que hoje chamamos de design" (MORAES, 2008).

Estudos e pesquisas foram feitos em inúmeras áreas de atuação, entre elas o design, e a ergonomia, que buscam na produção de conhecimentos, ajudar na compreensão de como conceber produtos mais fáceis de utilizar, que sejam mais desejáveis e ainda que possam trazer um diferencial para o consumidor, de acordo com Moraes e Kruchen (2016), que consideram ainda que esses aspectos são fundamentais no mercado competitivo contemporâneo. Segundo os autores, exemplos de pesquisas são encontrados em Norman (1998), que se direcionou em estudos sobre a usabilidade de produtos; e em Nielsen (2007), que pesquisou diversos produtos e artefatos informatizados. Os resultados que têm sido obtidos nesta área de pesquisa ajudam o designer a criar características específicas no projeto de produtos que facilitem sua utilização. Ainda segundo Moraes e Kruchen (2016), esforços foram feitos ao longo do tempo, na tentativa de compreensão da relação entre características físicas e funcionais dos artefatos e a eficácia de uso dos produtos.

A partir desse momento, de acordo com Moraes e Kruchen (2016), surgem termos como usabilidade, user experience (ou experiência de usuários) e product experience (ou experiência com produtos), além da dimensão emocional, na relação entre o indivíduo e um produto. Esta última, pautada a partir da tentativa de responder a perguntas como: Por que as pessoas se apegam a determinados objetos sem que haja uma explicação lógica em termos de praticidade e utilidade? ou Como a estética dos produtos influencia a escolha dos indivíduos? Essa conjuntura levou ao surgimento do movimento do Emotional Design no final da década de 1990 (MORAES; KRUCHEN (2016).

No que diz respeito a Ergonomia, novos estudos explorados vão além dos aspectos métricos, de segurança e de biomecânica. Agora, para garantir que os produtos se adequem ao mercado, objetivam-se quesitos ligados à usabilidade, conforto, percepção, sensações e fatores emocionais ligados ao prazer. Portanto, a manipulação destes fatores, que são reconhecidos como referências para o consumidor quando resolve escolher determinado produto, é fundamental para o aumento da competitividade
Realização:

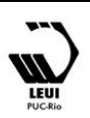




\section{$16^{\circ}$ \\ ERGODESIGN USIHC CINAHPA}

deste no mercado (PEREIRA; CARRASCO, 2004).

Quanto às pesquisas no campo do Design, têm-se, no desenvolvimento de modelos conceituais de experiências e estratégias para se projetar experiências, o processo de conceitualização da experiência afetiva, que acontece na interação entre pessoas e produtos. Nesse campo também considerado novo, são observados, na relação entre pessoas e produtos de consumo, os princípios fundamentais do amor, estudo desenvolvido por Russo e Hekkert (2008), que diz que tais princípios são considerados "modos de ação fixos" prédeterminados, que desencadeiam o que é experiência como amor na interação com produtos de consumo. Os pesquisadores propõem que os designers que têm um conjunto claro de informações referentes aos conceitos experienciais, conseguem desenvolver sua própria criatividade de forma livre e conseguem também ter mais controle sobre seu trabalho. (RUSSO; HEKKERT, 2008).

Assim, percebe-se que o homem, enquanto usuário de produtos e artefatos que o cercam, tem sido mais valorizado (tanto no campo do design quanto na ergonomia), em seus aspectos emocionais afetivos e sensíveis. Por conseguinte, pautado nestas questões, discute-se as noções de Identidade, Apropriação, Mediação, Prazer e Interação, apoiados nos estudos sobre análise sensorial e de conforto, de Pereira et al (2004); a estas noções, relacionamos aspectos pertinentes aos estudos sobre a experiência amorosa entre pessoas e objetos, de Russo e Hekkert (2008). Além disso, busca-se investigar a influência e a percepção destes conceitos na relação de consumo homem x objeto (produto). Tal investigação se deu por meio de pesquisa de campo ante aos consumidores de um determinado supermercado de produtos de consumo alimentício, onde submeteu- $16^{\circ}$ Ergodesign - Congresso Internacional de Ergonomia e Usabilidade de Interfaces Humano Tecnológica: Produto, Informações Ambientes Construídos e Transporte

$16^{\circ}$ USIHC - Congresso Internacional de Ergonomia e Usabilidade de Interfaces Humano Computador

CINAHPA | 2017 - Congresso Internacional de Ambientes Hipermídia para Aprendizagem. se um questionário de satisfação, adaptado a questionários auto-aplicáveis, de modo empírico e agregado à uma entrevista semi-estruturada.

\section{Histórico do desenvolvimento de produtos}

Os instrumentos confeccionados pelo homem na pré-história, demarcaram o início da ergonomia e do design, visto que estes seriam os primeiros vestígios representantes das tentativas elementares de concretizar a ideia em uma forma. Esta habilidade de confeccionar e utilizar ferramentas diferencia o homem do animal, pois para Heskett (2008), fazer design é justamente uma prática e atividade de criar formas e não apenas a capacidade de criar artefatos, de acordo com Paschoarelli (2008).

Ressalta-se, portanto, a importância dos primeiros artesãos, que iniciaram as invenções e desenvolvimentos técnicos até hoje ininterrupta. Estes, ao procurarem ao aliar o conforto, a manuseabilidade e a facilidade na construção de ferramentas e utensílios, desenvolveram conceitos chaves do design ergonômico. Tais conceitos embasaram as atividades cotidianas como raspar, cortar, moer, costurar, se abrigar do frio, além da autodefesa. $\mathrm{O}$ que evidencia que $\mathrm{o}$ desenvolvimento de produtos inicia-se com a história do próprio homem (GUIDON, 1992; SUGGS, 1962; PASCHOARELLI; 2008).

\subsection{Evolução dos produtos}

A evolução da ergonomia e do design, pode ser entendida por meio dos estudos arqueológicos, a partir de vestígios da primeira peça de roupa feita pelo homem, a cerca de $10 \mathrm{mil}$ anos, assim, como o calçado, outra peça usada pelas primeiras civilizações, para proteção dos pés, onde utlizavase madeira ou couro como matéria prima, segundo Silva (2001) apud Paschoarelli (2008). Como

Realização:




\section{$16^{\circ}$ \\ ERGODESIGN USIHC CINAHPA}
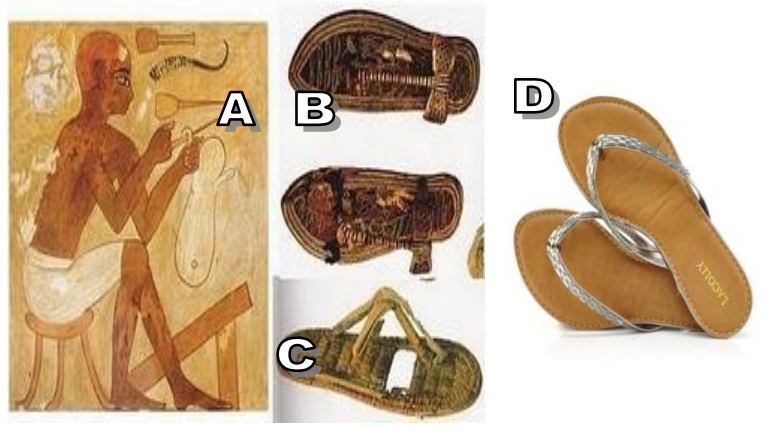

FIGURA A: O artesão de sandálias, representação. $18^{\circ}$ Dinastia, 1567-1320 a.C; FIGURA B: sandálias de madeira com detalhes em ouro, tesouro de Tutancâmon, $18^{\circ}$ Dinastia; FIGURA C: sandália egípcia feita de fibras de plantas - Fonte: Livro "The Art of the Shoe"; FIGURA D: sandália feminina, 2017 - fonte: VIZZENT (2017).

Além de roupas, são encontrados outros objetos como ferramentas com valor para sobrevivência do homem, tais objetos tinham a função de raspar, cortar, furar. Isto seria útil para confecção de roupas ou para cortar carne, madeira ou outros materiais macios (PASCHOARELLI, 2008).

Tais objetos têm provável influência nos similares contemporâneos, como pode ser observado nas figuras abaixo:
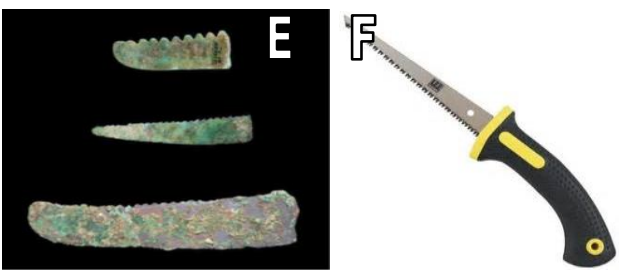

FIGURA E: Conjunto de pequenas serras, serrotes ou lâminas de foice de cobre do povoado pré-histórico de Leceia. Calcolítico Pleno.

Fonte: catálogo Arqueologia do Concelho de Oeiras: do Paleolítico Inferior arcaico ao século XVIII. 2011; FIGURA F: Serrote Profissional Multiuso - fonte: FERRAMIX (2016).

Dessa forma, segundo Paschoarelli (2008), o homem começa a pensar como cada um desses instrumentos e utensílios para o desenvolvimento das atividades do cotidiano deveriam ser. $\mathrm{O}$ autor observou características conceitos chaves do que hoje se chama de ergonomia, design e design ergonômico. (PASCHOARELLI, 2008). $16^{\circ}$ Ergodesign - Congresso Internacional de Ergonomia e Usabilidade de Interfaces Humano Tecnológica: Produto, Informações Ambientes Construídos e Transporte

$16^{\circ}$ USIHC - Congresso Internacional de Ergonomia e Usabilidade de Interfaces Humano Computador

CINAHPA | 2017 - Congresso Internacional de Ambientes Hipermídia para Aprendizagem.

\subsection{Origens do Design}

Os primeiros modelos de produtos produzidos em série pelo método artesanal, se deram no período medieval, onde nas cidades mais ricas, foram criados laboratórios que desenvolviam utensílios de uso doméstico, com reconhecido valor artístico e notável qualidade produtiva, de acordo com De Moraes (1997). Posteriormente, no século XVII, as instituições manufatureiras são fundadas pelo mecenato, visando auxiliar os artistas e os artesãos . No entanto, a mecanização da produção só foi impulsionada, na metade do séc. XVIII, na Inglaterra, e a partir disso o processo de industrialização disseminou-se por toda a Europa ainda no final do século XVIII, desenvolvendo-se na França, Alemanha e Itália (DE MORAES, 1997).

Para Cardoso (2013), o design surge nos séculos XVIII e XIX, objetivando a organização da produção industrial em série, período onde o consumo de diversos bens já estava ao alcance da população. Buscou-se, gradativamente, uma aproximação com profissionais oriundos de áreas criativas distintas, tais como artistas e arquitetos, além de governos, de indústrias, de comerciantes e de instituições de ensino. O anseio era o de acrescentar uma qualidade estética e visual nos produtos com o objetivo de instigar o consumo, pois se temia que a produção seriada poderia acarretar perda de beleza e qualidade dos produtos (DE MORAES, 1997).

Ademais, as pesquisas recentes no âmbito do Design tem apontado para a relação dos humanos com os produtos no âmbito emocional. De maneira que os novos desafios passam pela questão da adequação dos artefatos às necessidades emocionais do homem, pois os aspectos tangíveis como a antropometria já tem sido estudados há muito tempo (SCOLARI, 2008).

Portanto, a discussão sobre emoção no campo do Design, se intensifica nos anos que seguem, onde uma parte dos estudos da área tem a preocupação em entender o significado emocional das relações que perpassam os produtos e as pessoas, de forma que os termos relacionados à questão são
Realização:
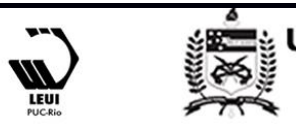


\section{$16^{\circ}$ \\ ERGODESIGN USIHC CINAHPA}

Emotional Design, Design and Emotion, Design Emocional e Design e Emoção. (NORMAN, 2004), (GREEN, 1999), (IIDA, 2006), (DAMAZIO, 2006) apud (SCOLARI, 2008).

\subsection{Surgimento da Ergonomia}

No campo da ergonomia, sua sistematização se deu na Revolução Industrial, devido às condições precárias de trabalho. No século XIX, com o taylorismo, a preocupação era adaptar o homem ao trabalho, onde se separava o trabalho físico do intelectual, e se desprezavam aspectos individuais dos trabalhadores, segundo Dejours (1988).

A Ergonomia se origina durante a II Guerra Mundial, preocupada com os aspectos físicos e biomecânicos, de interface Homem-Máquina. (MORAES, 1994)

O termo ergonomia foi criado e passa a ser adotado oficialmente em 1949, quando da criação da Ergonomics Research Society, a primeira sociedade de ergonomia, que reunia psicólogos, fisiologistas e engenheiros ingleses, em prol da resolução dos problemas nesse campo de conhecimento (HIRATSUKA, 1996).

No entanto, com o desenvolvimento tecnológico, houve uma nova preocupação, o foco se dá nos processos cognitivos e a carga informacional do trabalho. (MORAES, 1994).

Segundo Moraes (2000) apud Mont'Alvão (2008), em novembro de 1984, no primeiro congresso de Ergodesign, ocorrido em Montreux , a Ergonomia foi definida como "uma nova ciência, que estuda o comportamento e reações do homem em relação ao seu trabalho, à maneira que ele opera e ao ambiente", havendo a junção da Ergonomia ao processo do Design, criando-se o termo Ergodesign, conceito desenvolvido para construir uma ligação entre as duas disciplinas, de maneira que isso resultasse garantia da satisfação dos requisitos ergonômicos nos projetos de design.

Por fim, para Khalid (2004) apud Mont'Alvão (2008), uma nova perspectiva de pesquisa está surgindo na área de fatores humanos e ergonomia, $16^{\circ}$ Ergodesign - Congresso Internacional de Ergonomia e Usabilidade de Interfaces Humano Tecnológica: Produto, Informações Ambientes Construídos e Transporte

$16^{\circ}$ USIHC - Congresso Internacional de Ergonomia e Usabilidade de Interfaces Humano Computador

CINAHPA | 2017 - Congresso Internacional de Ambientes Hipermídia para Aprendizagem.

o “projeto ergonômico afetivo" (MONT’ALVÃO, 2008).

\section{Identidade, prazer e interação}

Aspectos de identidade e apropriação são considerados fundamentais para o entendimento da relação entre o homem e seu meio. No que diz respeito à Identidade, esta é definida pelas características próprias do produto e pode ser analisada tanto do ponto de vista individual quanto coletivo, podendo ainda ser parâmetro para a distinção e reconhecimento. Tal referência de distinção, de criação de diferencial, favorece além do fortalecimento e coesão de um grupo, a distinção daquele que escolhe o objeto, de modo que passa a haver a valorização do indivíduo e, como já mencionado antes, o aumento da competitividade do produto (PEREIRA et al. 2004). Percebe-se mesmo, uma situação de inclusão e coesão,

integral ou parcial, em grupos que se constituem em torno de uma identidade cultural ou econômica, produzida por fatores simbólicos e/ou tangíveis. Haja visto os resultados alcançados por alguns produtos regionais que, com base no fator identidade, obtêm diferencial competitivo com a lógica coletiva e com a íntima e exclusiva ligação entre o produto e a região. Do ponto de vista econômico e de mercado, é possível deduzir a importância do fato do produto com 'sabor' local (SAFFAR et al. 2004) apud (PEREIRA, et al. 2004, p. 2).

A ideia de produtos que encorajam e facilitam a construção da auto-identidade de uma pessoa, está relacionado, segundo Russo e Hekkert (2008), ao significado Simbólico (Social), que há na relação entre o homem e o produto . Este significado é um dos elementos que fazem parte dos estudos relacionados a experiências afetivas envolvidas na interação humano- produto. O significado
Realização:

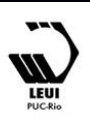




\section{$16^{\circ}$ \\ ERGODESIGN USIHC CINAHPA}

Simbólico (Social) diz respeito aos significados que são expostos a outras pessoas, num ambiente social. Os autores afirmam que, além de confirmação desta identidade, os produtos podem satisfazer prazeres sociais. Estes prazeres são obtidos por meio da interação com outros (JORDAN, 2002), (RUSSO; HEKKERT, 2008).

Assim, este princípio está relacionado a dois cenários específicos: (1) a ideia de que pessoas procuram produtos que já possuem uma identidade e que, por possuir este produto, esperam que esta identidade seja vista como deles próprios e (2) o fato de que pessoas querem comunicar sua identidade, valores intrínsecos, e crenças através dos produtos (GOVERS, 2004) apud (RUSSO; HEKKERT, 2008).

Portanto, a identidade, tanto quanto o prazer, seriam fundamentais para a apropriação, pois o homem se apropria da cultura para se relacionar com o meio, e o faz porque tem uma identidade, em nível individual e coletivo (PEREIRA et al, 2004).

\section{Apropriação e mediação}

A discussão de Pereira et al (2004) considera a "teoria da mediação" de Jean Gagnepain (1994), para que se entendam as relações entre identidade e apropriação. Aqui se ressalta que o ser humano é dividido, por ser capaz de sair da condição do natural, da categoria de Ser humano e deixar de pertencer a um mundo único, onde admitir a divisão, leva "à interpretação, à percepção, que é individual, e leva também à apropriação." (PEREIRA et al, 2004).

Admite-se portanto, outras racionalidades que distinguem o Ser humano do animal. Estas estão entre a lógica e o contra-senso; o trabalho e o lazer; o individual e o coletivo; o desejo e o direito. As $16^{\circ}$ Ergodesign - Congresso Internacional de Ergonomia e Usabilidade de Interfaces Humano Tecnológica: Produto, Informações Ambientes Construídos e Transporte

$16^{\circ}$ USIHC - Congresso Internacional de Ergonomia e Usabilidade de Interfaces Humano Computador

CINAHPA | 2017 - Congresso Internacional de Ambientes Hipermídia para Aprendizagem. quais se inserem respectivamente nos planos da linguagem e da consciência; no plano da atividade e do comportamento; no plano da sociedade e do singular e no plano da emoção e da moral. O ser humano, segundo a teoria, funciona de acordo com a dialética dessas quatro racionalidades.

(PEREIRA et al, 2004).

Ainda de acordo com Pereira et al (2004), esses planos vão se concretizar através da mediação: do signo, do utensílio, da pessoa, da norma. Ressaltase, portanto, que no plano do trabalho, dos produtos, da técnica, o utensílio vai permitir a mediação do trabalho, da atividade.

Ao observarmos estes planos de racionalidade, somos remetidos aos princípios da experiência amorosa, de Russo e Hekkert (2008). Neste estudo, percebe-se que o princípio do "compartilhamento de valores morais", está relacionado a uma ligação entre princípios morais e éticos de pessoas e produtos, que afirma que "Pessoas amam usar produtos através dos quais eles possam dividir, compartilhar valores éticos e morais" (RUSSO; HEKKERT, 2008).

Como exemplo, tem-se a ideia de consumo consciente, que é um movimento social baseado no impacto que as decisões de compra tem no meio ambiente, na saúde e bem estar do consumidor, onde a maior motivação relacionada ao consumo ético é o prazer que este tipo de consumo gera nas pessoas, de forma que consumir conscientemente leva à experiências de prazeres sociais, "uma forma abstrata de prazer que é experienciada quando um produto personifica certos valores e transfere um senso de responsabilidade ambiental para o usuário" (JORDAN, 2000) (RUSSO; HEKKET, 2008).

De acordo com Pereira et al (2004), este princípio apontado como referência amorosa, nos remete à 


\section{$16^{\circ}$ \\ ERGODESIGN USIHC CINAHPA}

$16^{\circ}$ Ergodesign - Congresso Internacional de Ergonomia e Usabilidade de Interfaces Humano Tecnológica: Produto, Informações Ambientes Construídos e Transporte

$16^{\circ}$ USIHC - Congresso Internacional de Ergonomia e Usabilidade de Interfaces Humano Computador

CINAHPA | 2017 - Congresso Internacional de Ambientes Hipermídia para Aprendizagem. dimensão do plano da emoção e da moral, que tem a norma como mediadora da racionalidade, relacionada ao plano do direito.

Considerando ainda Pereira et al (2004), o homem se diferencia do animal justamente por usar a razão para elaborar esse princípio de abstração, que organiza sua compreensão do mundo nesses quatro planos. E é somente através dos signos, dos utensílios, da produção que o homem consegue essa mediação, essa abstração. Por isso, o ser humano torna-se próprio e diferente do outro quando ele se apropria desses quatro planos, levado pela busca da singularidade. Assim, quando torna-se diferente, também sente-se obrigado a trocar, por uma questão de necessidade inata, o que evidencia seu caráter singular e universal.

Consequentemente, apropriação, troca e comunicação revelam-se como uma coisa só, pois

Essas ações vão ser feitas através da apropriação da língua no campo da linguagem. Vamos nos apropriar da língua, o português ou o mineirês, por exemplo, para nos tornar diferentes de outros grupos, para mantermos a nossa singularidade, nossa identidade (PEREIRA et al, 2004, p. 3).

Deste modo, o produto revela-se como mediador de nossas condutas, nos diversos planos, não somente no plano do trabalho; permite mesmo que sejamos singulares por meio da escolha e da apropriação de um conjunto particular de objetos. Ressalta-se ainda que, outra possibilidade que o produto nos dá é a de universalização, possível através dessa identificação material.

Ademais, essa apropriação em relação aos objetos é feita por meio da percepção que estabelecemos com o produto, a partir da comunicação, das tipologias, das cores, dos estilos e da forma como utilizamos tais produtos (PEREIRA et al, 2004). No entanto, segundo Pereira et al (2004), ao final, o que irá importar é apropriação que a pessoa fará do objeto, o poder que este objeto traz para que a pessoa se comunique, se individualize e assuma uma identidade.

\section{Apropriação e prazer}

Outra questão pertinente na relação entre pessoas e os objetos, são as expressões de prazer, sentimentos positivos decorrentes da apropriação dos objetos e suas qualidades, funcionalidades, sua precisão de funcionamento, facilidades de uso e a rapidez de comunicação proporcionadas por eles (PEREIRA et al, 2004).

De acordo com Moraes (2008), o prazer é incitado por um conjunto de experiências emocionais positivas, decorrentes de uma herança evolutiva do homem enquanto espécie, cerca de 2 a 4 milhões de anos, quando foi orientado por situações bem sucedidas no passado. Tais situações prazerosas foram ocasionadas pela comida, sexo, calor, sono confortável, atividades gregárias, etc (TIGER, 2000; MORAES et al, 2008).

No entanto, somente nos dois últimos séculos, com a industrialização, o modo de vida das pessoas foi transformado. $\mathrm{O}$ fato trouxe uma mudança drástica das fontes de prazeres humanos. $\mathrm{Na}$ contemporaneidade, esses prazeres dependem de produtos industrializados. Os designers, peçaschave desse processo industrial, contribuem, ao criarem fontes de novos prazeres. De acordo com Jordan (2000), existem inúmeros tipos de prazeres que podem ser investigados, ele os dividiu em quatro categorias: Prazer fisiológico, com origem em experiências sensoriais de origem sexual, tato, gosto e odor; o prazer de auto-realização, que vem da satisfação em realizar uma tarefa com sucesso; o prazer social, onde as pessoas sentem prazer em estar em grupo; e o prazer intelectual, no qual as pessoas sentem prazer em imaginar ou criar coisas, 


\section{$16^{\circ}$ \\ ERGODESIGN USIHC CINAHPA}

em observar objetos estéticos. (MORAES, 2008)

Nesse sentido, Hekkert (2006) pode ser lembrado quando afirma que pessoas amam interagir com produtos que são fisicamente prazerosos. Observase tal pontuação, nos seus estudos sobre a experiência afetiva, especificamente no princípio de amor denominado interação física prazerosa. $\mathrm{O}$ conceito deste princípio fala do quanto um produto pode gratificar os nossos sentidos. Considera-se ainda que, embora outros sentidos se envolvam na experiência do amor, a interação física prazerosa se refere às propriedades táteis de um produto.

(HEKKERT, 2006).

Pereira et al (2004), afirmam que, no quesito consumo, a tendência é que a pessoa ultrapasse a necessidade de compra e se envolva emocionalmente na busca da satisfação de outras necessidades, no caso, a necessidade de buscar prazer. Isto está relacionado a forma como as pessoas se apropriam com o produto. Elas o fazem através da representação formal, (texturas, linhas e cores) e, de sua "significação": ou seja, sua função de uso (trabalho, lazer, etc.) e sua função estética (ornamentação, identificação e distinção).

Desta forma, os objetos suscitam em nós, ao mesmo tempo, valores de uso e valores de estima que lhes são intrínsecos, pois

A multiplicidade e diversidade apresentadas pelo mercado, levam a um a singularidade possível pela a apropriação de um repertório específico e individual de objetos. Mas, ao mesmo tempo, e em função da presença de certas combinações e de certos estilos, ela nos permite estabelecer a comunicação com o outro e alcançar a universalidade (PEREIRA et al, 2004, p. 4).

Portanto, nossa compreensão de prazer sentida em relação aos objetos estará ligada à noção de conforto, ao bem-estar encontrado com a $16^{\circ}$ Ergodesign - Congresso Internacional de Ergonomia e Usabilidade de Interfaces Humano Tecnológica: Produto, Informações Ambientes Construídos e Transporte

$16^{\circ}$ USIHC - Congresso Internacional de Ergonomia e Usabilidade de Interfaces Humano Computador

CINAHPA | 2017 - Congresso Internacional de Ambientes Hipermídia para Aprendizagem. manipulação do objeto, com sua eficácia, simplicidade de uso ou mesmo, dificuldade de uso.

Assim, num primeiro estágio ao contato com o objeto, o julgamento será sempre baseado na referência do prazer, que condicionará fortemente a opinião sobre o produto, de maneira que quando o produto é examinado pela primeira vez, inconscientemente as pessoas fazem um somatório das sensações que o objeto as provoca. Elas perceberão essas sensações como prazerosas, indiferentes ou repulsivas. De acordo com Bonapace (2000), somente em um segundo momento, o usuário receberá outros estímulos com o uso do produto e o julgamento se tornará mais preciso.

\section{Métodos e técnicas}

A pesquisa realizada é do tipo exploratória descritiva, onde utilizou-se como sujeitos da pesquisa um público consumidor de um supermercado de bairro popular da cidade de São Luís - MA, composto por estudantes, donas de casa e empresários do setor alimentício. A amostra foi definida em 6 pessoas, com respondentes homens e mulheres de faixa etária entre vinte (20) e sessenta (60) anos de idade.

Coletaram-se dados entre a amostra sugerida, onde juntamente com o questionário e a entrevista, possibilitou-se coletar informações além das perguntas fechadas.

\subsection{Materiais}

-TCLE: Termo de Consentimento Livre e

Esclarecido

- Questionário de satisfação.

\subsection{Procedimentos}

1. Conversa inicial onde o participante da
Realização:

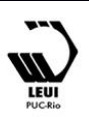




\section{$16^{\circ}$ \\ ERGODESIGN USIHC CINAHPA}

pesquisa pudesse se conscientizar dos riscos e benefícios envolvidos, além da garantia de seu anonimato.

2. Leitura e assinatura do termo de consentimento Livre e Esclarecido, afim de realizar uma pesquisa esclarecedora e ética.

3. Aplicação do Questionário de satisfação.

4. Entrevista semi-estrturada agregada aos questionários auto-aplicáveis de modo empírico, sendo os dois supervisionados, pois para Gil (2008), a entrevista estruturada se desenvolve a partir de uma relação fixa de perguntas, cuja ordem e redação permanece invariável para todos os entrevistados.

\section{Resultados}

Umas das questões propostas foi "Quais fatores influenciam na escolha de determinado produto de consumo?", de forma que abaixo (F 1), temos o esquema gráfico representante:

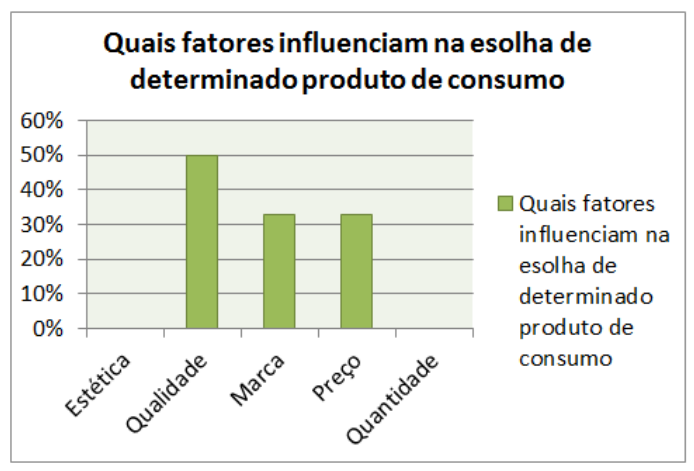

Figura 1

(fonte: autor)

A partir do gráfico acima obteve-se os seguintes resultados: o fator estético obteve $0 \%$ (zero por cento) de influência nas escolha de determinado produto; enquanto que o fator qualidade, obteve $50 \%$ (cinquenta por cento), ou seja, metade da amostra. Já os fatores confiança na marca e preço obtiveram 33, 3\% cada (trinta e três vírgula três), 2 pessoas para cada fator.

Quanto a pergunta seguinte, sobre se "Você utiliza $16^{\circ}$ Ergodesign - Congresso Internacional de Ergonomia e Usabilidade de Interfaces Humano Tecnológica: Produto, Informações Ambientes Construídos e Transporte

$16^{\circ}$ USIHC - Congresso Internacional de Ergonomia e Usabilidade de Interfaces Humano Computador

CINAHPA | 2017 - Congresso Internacional de Ambientes Hipermídia para Aprendizagem. a embalagem do produto após o consumo do conteúdo?" obtivemos como resultado o gráfico F2. Com resultados divididos em duas partes, a pergunta foi relacionada a produtos enlatados ou de conserva, onde $83,3 \%$ disse que sim, reutiliza a embalagem do produto. Já $16,7 \%$ demonstra que só às vezes reutiliza a embalagem do produto de consumo.

\section{Você reutiliza a embalagem do produto após o consumo?}

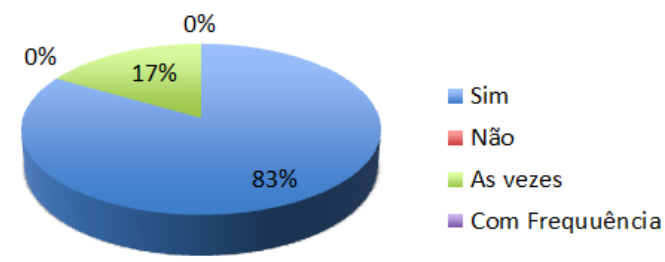

Figura 2

(fonte: autor)

Em relação à última pergunta, se "O aspecto visual estético da embalagem influencia na escolha do produto de consumo? (um produto de conserva, enlatado, por exemplo) ", obtivemos o gráfico F3 logo abaixo. Dos respondentes, $50 \%$ (cinquenta por cento) disseram que o aspecto visual não influência; enquanto os outros 50\% (cinquenta por cento) acreditam que existe influência visual sim, na escolha de um produto.

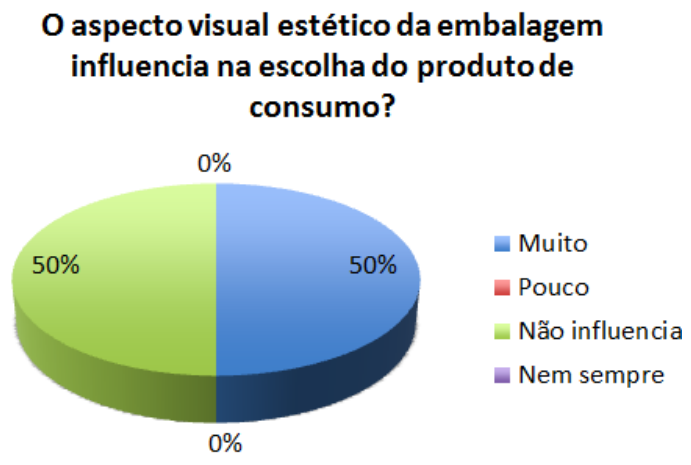

Figura 3

(fonte: autor)

\section{Discussão}

Realização:
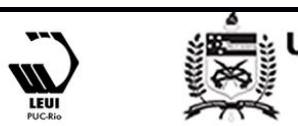


\section{$16^{\circ}$ \\ ERGODESIGN USIHC CINAHPA}

O objetivo deste estudo foi investigar as noções de apropriação, mediação, identidade, prazer e interação dos teóricos abordados e identificar a relação destas às variáveis da relação homem x objeto (produto).

Percebeu-se na primeira pergunta, sobre Quais fatores influenciam na escolha de determinado produto de consumo?", aspectos de construção do significado simbólico (social) de Russo e Hekkert (2008), pois o fator "qualidade" obteve 50\%, o que confirma a ideia de que pessoas buscam produtos que já possuem uma identidade, geralmente construída pela qualidade que o produto apresenta. Assim, ao consumirem tal produto, a identidade deste possa ser vista como deles próprios.

Sobre questão da reutilização da embalagem após o consumo, com 83,3\% dos respondentes dizendo que sim, reutilizam a embalagem apos o término do conteúdo, vê-se um dos princípios da experiência amorosa, de Russo e Hekkert (2008), o princípio do "compartilhamento de valores morais", relacionado a uma ligação entre princípios morais e éticos de pessoas e produtos. Pois ao reutilizar a embalagem, percebe-se a ideia de consumo consciente, evidenciando uma espécie de consumo ético. Este tipo de consumo consciente gera nas pessoas, experiências de prazeres sociais.

No que se refere à pergunta sobre se "O aspecto visual estético da embalagem influencia na escolha do produto de consumo?", obteve-se um resultado divido, o que não exclui os aspectos acima discutidos. Pois, ao perceberem que há um fator estético mediando o processo de comunicação com o produto (suas tipologias, cores, estilos), as pessoas já começaram a fazer apropriação do objeto, segundo Pereira; Carrasco, (2004). Assim, o que irá importar mesmo, de acordo com os autores supracitados, será o poder que este objeto $16^{\circ}$ Ergodesign - Congresso Internacional de Ergonomia e Usabilidade de Interfaces Humano Tecnológica: Produto, Informações Ambientes Construídos e Transporte

$16^{\circ}$ USIHC - Congresso Internacional de Ergonomia e Usabilidade de Interfaces Humano Computador

CINAHPA | 2017 - Congresso Internacional de Ambientes Hipermídia para Aprendizagem.

trouxe para que a pessoa se comunicasse, individualizasse e assumisse uma identidade.

\section{Considerações finais}

Consideramos, portanto, que a emoção desempenha um papel importante na decisão das pessoas, pois, na escolha de um determinado produto, há um forte componente emocional. E os designers, por sua vez, têm a função de incorporar esses componentes emocionais em seus projetos. Logo, por estar evidente, o fator emocional tem ganhado importância por parte de pesquisadores, que passaram a desenvolver métodos para entender esse fator na relação entre pessoas e objetos.

Percebe-se esse processo, tanto na área de design quanto de ergonomia - que se colocam como responsáveis enquanto disciplinas que norteiam o desenvolvimento dos objetos que mediam a relação do homem com o mundo.

Assim, apoiados nos autores abordados, consentimos que há necessidade de aprofundamento dos estudos que perpassam o entendimento da relação dos objetos com o homem e a questão emocional pertinente a esta.

Consideramos ainda a contribuição desta discussão para designers que não possuem um esclarecimento enraizado às noções de emoção, mediação e prazer abordadas no artigo.

Podem ser apontadas nesse trabalho ainda, algumas limitações, dentre as quais, a necessidade de uma amostra maior, em segmentos diferentes da sociedade, com um poder aquisitivo maior. $\mathrm{O}$ que poderia confirmar algumas variáveis que se mostraram limitantes, no caso o aspecto do poder aquisitivo. Pois surge o questionamento, até que ponto o poder de consumo interfere na percepção estética enquanto fator de influência na escolha do produto de consumo? Um poder de consumo baixo pode limitar a escolha de um produto que seduz 
$16^{\circ}$ USIHC - Congresso Internacional de Ergonomia e Usabilidade de USIHC Interfaces Humano Computador

CINAHPA | 2017 - Congresso Internacional de Ambientes Hipermídia para Aprendizagem.

pelo aspecto estético-formal?

Sugere-se, por fim, a realização dessa pesquisa em estudos futuros para o aprofundamento das questões acima levantadas.

\section{Referências}

BONAPACE, L. Pleasure-based human factors and the SEQUAM: sensorial quality assessment method. Politecnico de Milão, 2000.

CARDOSO, João Luís. Arqueologia do Concelho de Oeiras: do Paleolítico Inferior arcaico ao século XVIII. Câmara Municipal de Oeiras, 2011.

CARDOSO, Rafael. Design para um mundo complexo. São Paulo: Cosacnaify, 2013

DE MORAES, Dijon. Limites do design Studio Nobel, 1997.

DEJOURS, Christophe. A loucura do trabalho. 1992.

HEKKERT, Paul. Design aesthetics: principles of pleasure in design. Psychology science, v. 48, n. 2 , p. 157, 2006.

HESKETT, John. Design/John Heskett; revisão técnica Pedro Fiori Fernandes. São Paulo: Ática, 2008.

HIRATSUKA, Tei Peixoto. Contribuições da ergonomia e do design na concepção de interfaces multimídia. 1996. Tese de Doutorado. Universidade Federal de Santa Catarina.

IIDA, Itiro. Ergonomia. Projeto e produção. São Paulo: Edgard Blücher, 1997.

JORDAN, Patrick W. Designing pleasurable products: An introduction to the new human factors. CRC press, 2002.

MONT'ALVÃO, Claudia; DAMAZIO, Vera
(Ed.). Design ergonomia emoção. Mauad Editora Ltda, 2008.

MORAES, Dijon de, and Lia KRUCKEN.

"Design e Transversalidade. BH." Cadernos de Estudos Avançados em Design, Caderno 2, v. 12,2016 .

MORAES, Dijon de, and Sergio P., MARTÍNEZ. "Design e Cultura. BH."

Cadernos de Estudos Avançados em Design, v.11, 2016.

MORAES, Anamaria. Ergonomia: a Humanização do Trabalho, da Tecnologia, das Organizações, da Engenharia e do Design. In: Anais do Congresso Brasileiro de Engenharia de Produção. João Pessoa. 1994.

NIELSEN, J., Usabilidade na web: projetando websites com qualidade. Rio de Janeiro: Elsevier, 2007.

PASCHOARELLI, Luis Carlos. A Pré-história do Design e da Ergonomia.

PEREIRA, A. et al. Análise sensorial e de conforto como referência para a certificação e a valorização do produto. In: 13 Congresso Brasileiro de Ergonomia, ABERGO, Fortaleza. 2004.

RUSSO, Beatriz; HEKKERT, Paul. Sobre amar um produto: os princípios fundamentais. Design, ergonomia e emoção. Rio de Janeiro: Mauad X: FAPERJ, 2008

SCOLARI, SÉRGIO HENRIQUE PRADO. "Design e emoção: um modelo de círculos de referências de emoções em produtos." São Paulo: Universidade Estadual Paulista. Faculdade de Arquitetura, Artes e Comunicação (2008). 